Recibido: 01/04/2021 --- Aceptado: 05/08/2021 --- Publicado: 16/09/2021

\title{
DISPUTAS DISCURSIVAS. IDEAS SOBRE LA LIBERTAD EN LOS DESEMBARCOS INICIALES DEL MOVIMIENTO NEOLIBERAL EN ARGENTINA
}

\section{DISCURSIVE DISPUTES. IDEAS SOBRE LA LIBERTAD IN THE EARLY ARRIVALS OF THE NEOLIBERAL MOVEMENT IN ARGENTINA}

María Paula de Büren'1: Universidad de Buenos Aires. Argentina. pauladeburen@yahoo.com.ar

\section{Cómo citar el artículo:}

De Büren, M. P. (2020). Disputas discursivas. Ideas sobre la libertad en los desembarcos iniciales del movimiento neoliberal en Argentina. Revista de Comunicación de la SEECI, 54, 25-48. http://doi.org/10.15198/seeci.2021.54.e698

\section{RESUMEN}

A mediados del siglo XX en una superficie histórica signada por disputas propias de la Guerra Fría; integrantes de Mont Pèlerin Society, con objeto de dar difusión a entramados conceptuales destinados a dar batalla a perspectivas y modelos que -en algún grado- permiten la legitimación de demandas obreras y entorpecen procesos de extracción de plusvalía, crean diversos institutos a lo largo de América Latina y el globo. Uno de ellos es, en el caso argentino, el Centro de Difusión de la Economía Libre (CDEL). El trabajo que presentamos a continuación releva los autores cuya obra ha sido difundida en la publicación periódica que editase dicho centro, así como, su procedencia institucional, el carácter de tales instituciones y la posición jerárquica que los mismos ocupaban en las entidades de origen. Ello con objeto de adentrarnos, a través del abordaje de un caso concreto, en el estudio del funcionamiento y las estrategias desplegadas por quienes se nucléan alrededor de Mont Pèlerin Society con objeto de dar batalla en el plano discursivo a opciones políticas, económicas y sociales antagónicas.

PALABRAS CLAVE: Neoliberalismo - Intelectuales orgánicos - Empresarios- Elites Disputas discursivas- Pos verdad - Argentina - Derechas.

\section{ABSTRACT}

1 María Paula de Büren: Dra. En Ciencias Sociales (UBA-Facultad de Ciencias Sociales), Magter en Desarrollo Económico (UNIA- Sede La Rábida), Lic. en Economía (UNVM). Docente e investigadora (UBA-Fac de Ciencias Sociales, UNPAZ). 
The Mont Pèlerin Society's members created different institutes in Latin America and around of the word at middle of XX century to expand a discursive directed to dispute antagonist socio economics models. The Centro de Difusión de la Economía Libre of Argentine was one of them. This work relieve the authors whose writings have been disseminated by its periodic publication- Ideas Sobre la Libertad-, the institutional sources of them, the kind of institution and the hierarchical position occupied by them in these institutions. This with the object to put attention on those institutionals that suppor the neoliberal project.

KEYWORDS: Neoliberalism - Organic Intellectuals - Businessmen - Elites - Discursive Disputes - Post-truth - Argentina- Rights.

\section{DISPUTAS DISCURSIVAS. IDEIAS SOBRE LIBERDADE NOS ATERROS INICIAIS DO MOVIMENTO NEOLIBERAL NA ARGENTINA.}

\section{RESUMO}

Em meados do século XX em uma superfície histórica marcada por disputas típicas da Guerra Fria; Membros da Sociedade Mont Pèlerin, com o objetivo de disseminar marcos conceituais destinados a combater perspectivas e modelos que - em certa medida permitem a legitimação das demandas dos trabalhadores e dificultam os processos de extração de ganhos de capital, criam diversos institutos pela América, e o mundo. Um deles é, no caso argentino, o Centro de Difusão da Economia Livre (CDEL). Este trabalho revela os autores cuja obra foi divulgada na publicação periódica editada por esse centro, bem como a sua origem institucional, a natureza de tais instituições e a posição hierárquica que ocupavam nas entidades de origem. Isso para aprofundar, por meio da abordagem de um caso específico, no estudo do funcionamento e das estratégias implantadas por aqueles que estão nucleados em torno da Sociedade Mont Pèlerin para lutar no plano discursivo a opções políticas, econômicas e sociais antagônicas.

PALAVRAS CHAVE: Neoliberalismo - Intelectuais orgânicos - Empresários - Elites - Disputas discursivas - Pós-verdade - Argentina - Certo.

\section{INTRODUCCIÓN}

Bajo el tíltulo "Estrategias de desinformación: Fake News y Fact-Checking" la convocatoria a este número de la Revista de Comunicación de la SEECI certeramente nos advierte:

La desinformación, fenómeno definitorio de nuestro tiempo, (...) forma parte de las principales preocupaciones (...). [Se trata de una] crisis (...), con efectos como la falta de confianza en la calidad de la información recibida (...), en el 
papel de las instituciones públicas o privadas (...) y en la democracia en sí misma (Revista de Comunicación de la SEECI, 2021)

En consonancia con ello la publicación invita a presentar escritos resultantes de investigaciones abocadas a la comprensión de fenómenos de desinformación en general y de las fake news y el fact-checking en particular.

El escrito que a continuación damos inicio aborda un caso. Se introduce en el análisis de una publicación periódica concreta ligada a una organización que busca nuclear a actores vinculados a fracciones de la derecha internacional preocupadas por el avance del comunismo, el keynesianismo y el Estados de Bienestar. Esto, con objeto de visibilizar prácticas que, si bien preceden y difieren de los actuales procesos de desinformación caracterizados por la expansión de fake news, pueden considerarse un antecedente de tales en tanto formas de difusión de interpretaciones ${ }^{2}$ de la realidad social destinadas a intervenir en el devenir político e histórico de las comunidades y naciones.

Siguiendo las investigaciones de diversos autores podríamos describir el neoliberalismo como un proyecto global articulado desde mediados del Siglo XX en Mont Pèlerin Society (1947) (Anderson, 2003; Denord, 2002; Hartwell, 1995; Murillo, 2015; de Büren, 2015; de Büren, 2013; Morresi, 2008). Dicha asociación reúne a intelectuales, empresarios y políticos con objeto de enfrentar el avance del comunismo y de cualquier otra forma de direccionamiento estatal de la economía, entre ellas, las opciones socialistas, estatal bienestaristas y keynesianas. Mont Pèlerin Society entiende que las mencionadas formas se han expandido en el globo debido a la difusión de determinados modos de interpretar la historia y la realidad social; entonces - según su propio diagnóstico (Hartwel, 1995)- para darles pelea es preciso: deslegitimarlas socialmente mediante la crítica, escribir una nueva utopía frente a ellas -el nuevo liberalismo- y difundir las construcciones discursivas resultantes en todos los rincones del planeta. Ello con objeto de influir en el devenir político y social real de las naciones, más concretamente, detener el avance del comunismo, del socialismo y similares. Así es que, entre múltiples estrategias, se proponen la creación de una red internacional de personas encargadas la difusión de sus ideas, a la fundación de instituciones dedicadas al seguimiento de las políticas públicas de alta dirección y a la intervención política directa. En dicha dirección orientará su accionar a incorporar su entramado discursivo en las currículas universitarias y a fundar instituciones dedicadas a la difusión y re-adaptación de su andamiaje interpretativo en las distintas realidades locales de los distintos países del globo (Denord, 2002; Steinberg, 1995; Anderson, 2003, de Büren, 2015, Murillo, 2015).

\footnotetext{
${ }^{2}$ Interpretaciones cuya expansión no obedece su apego a la verdad en el sentido que nos enseñase la concepción aristotélica de verdad, es decir, como el correlato entre nuestro pensamiento expresado en lenguaje y la realidad, sino a la intención de intervenir sobre el devenir político, social y económico de los pueblos, cuestión en la que el presente artículo no se introduce ya que ha sido desarrollado en otros trabajos de la autora (de Büren, 2019, de Büren. 2020).
} 
En la República Argentina, esta inserción se hace efectiva -tras del derrocamiento del peronismo a manos de la Revolución Libertadora y en pleno momento de liderazgo norteamericano en el mundo occidental- a través de la figura de Alberto Benegas Lynch y del Centro de Difusión de la Economía Libre. Desde esta institución se organizan conferencias y publicaciones, entre ellas, la revista Ideas sobre la Libertad editada en el periodo 1958-1989 con objeto de difundir el marco conceptual monpelerines en Argentina (de Büren, 2020a; de Büren, 2014; de Büren, 2015).

A partir de la información disponible en el corpus compuesto por la revista Ideas sobre la Libertad en el total del periodo en el que fuese publicada, hemos elaborado una base de datos que, tras su procesamiento, nos ha permitido adentrarnos en elementos centrales de esta red: autores, instituciones nacionales, regionales y extranjeras que los mismos representan, origen de las publicaciones no periódicas difundidas por el CDEL, fuentes locales, regionales y extranjeras de aprovisionamiento discursivos y espacios de amplificación local.

\section{OBJETIVOS}

En tanto Ideas sobre la Libertad se constituye en un dispositivo destinado a introducir y amplificar en el territorio argentino el entramado discursivo monpelerines a través de la re-publicación de artículos divulgados en el extranjero, su traducción al español cuando fuese necesario y la traducción a la realidad local de su marco interpretativo e ideario; cabe preguntarnos, ¿Cuáles son las fuentes de procedencia de los enunciados que allí se pronuncian? ¿Qué actores los producen? ¿Desde qué posiciones de sujeto los formulan? ¿A partir de qué redes institucionales y articulaciones estratégicas? Tales, son las preguntas que específicamente intentaremos abordar en este relevamiento o, dicho en otros términos, buscaremos aquí introducirnos -a partir del análisis de una de las publicaciones periódicas de uno de los centro de difusión de Mont Pèlerin Society- en lo que Michel Foucault (2002) denomina "instancias de delimitación" del movimiento neoliberal.

\section{METODOLOGÍA}

El escrito que iniciamos a continuación puede parecer de tediosa lectura por la cantidad de información que releva. Sintetizamos los datos procesados en tablas que presentan los porcentajes relativos de participación de manera decreciente como forma de agilizar su lectura. No dudamos de su despliegue y exposición, puesto que, consideramos que el relevamiento, no sólo del tipo de institución; sino también de su identidad y la de sus autores, contribuye a la rigurosidad de este trabajo y constituye un aporte válido para investigadores abocados al estudio y análisis del despliegue del movimiento neoliberal nucleado en Mont Pèlerin Society y permite visibilizar el entramado internacional de este movimiento.

En términos metodológicos apelamos al abordaje genealógico y arqueológico que desarrollará Michel Foucault (2002, 1979), en tal sentido, el artículo rescata algunos enunciados proferidos por este movimiento, como las titulaciones de algunos de los artículos difundidos, así como las superficies desde las cuales los mismos emergen y 
De Büren, M. P. Disputas discursivas. Ideas sobre la libertad en los desembarcos iniciales del movimiento neoliberal en Argentina

circulan, los espacios de poder y actores o más precisamente las posiciones de sujetos desde las cuales se pronuncian.

\section{RESULTADOS}

El análisis de publicaciones difundidas en Ideas Sobre la Libertad en su periodo de vigencia, más específicamente, las obras de los autores que en ella se reproducen y su procedencia institucional nos permite observar el carácter político y empresarial de esta publicación. Podemos observar el modo en que unas de las publicaciones forjadas al interior del movimiento monpelerines, al tiempo que, se atribuye a si misma un carácter no lucrativo y unos objetivos limitados a la difusión de valores e ideas en torno a la libertad; se sostiene de manera real y efectiva en una red internacional de espacios empresariales y asociaciones con claro intereses de defensa de intereses de clase. La superficie material desde la que emergen estos enunciados y sostienen su circulación permite ahondar en la significación.

\section{DISCUSIÓN}

\subsection{Autores difundidos}

Nos adentramos a observar los autores y obras difundidas en la revista Ideas Sobre la Libertad entre diciembre de 1958 y diciembre de 1989, es decir, en sus números 1 a 54. La Tabla 1 -disponible a continuación- recoge la nómina de autores cuyos trabajos eran allí publicados o re-publicados y la cantidad de artículos presentados por cada uno ${ }^{3}$.

${ }^{3}$ La revista publica artículos completos, frases y fragmentos de escritos. La Tabla 1 fue elaborado exclusivamente en base al relevamiento artículos completos. 
De Büren, M. P. Disputas discursivas. Ideas sobre la libertad en los desembarcos iniciales del movimiento neoliberal en Argentina

Tabla 1. Autores difundidos en Ideas Sobre la Libertad. Cantidad de artículos. Diciembre de 1958-Diciembre 1989

\begin{tabular}{|c|c|c|}
\hline Autor & Total & Porcentaje \\
\hline Editorial & 35 & \\
\hline Read, Leonard E & 32 & $6,9 \%$ \\
\hline Benegas Lynch, Alberto & 32 & $6,9 \%$ \\
\hline Sennholz, Hans F. & 18 & $3,9 \%$ \\
\hline Benegas Lynch, Alberto (h) & 18 & $3,9 \%$ \\
\hline von Mises, Ludwig & 16 & $3,4 \%$ \\
\hline Hazlitt, Henry & 14 & $3,0 \%$ \\
\hline Russell, Dean & 13 & $2,8 \%$ \\
\hline Tagle, Manuel & 10 & $2,2 \%$ \\
\hline von Hayek, Friedrich & 9 & $1,9 \%$ \\
\hline Poirot, Paul L. & 9 & $1,9 \%$ \\
\hline Chamberlin, William Henry & 9 & $1,9 \%$ \\
\hline Carson, Clarence B. & 7 & $1,5 \%$ \\
\hline Winder, George & 6 & $1,3 \%$ \\
\hline Abdala, Raúl Oscar & 6 & $1,3 \%$ \\
\hline Reig, Joaquín & 5 & $1,1 \%$ \\
\hline Zylberberg, Meir & 5 & $1,1 \%$ \\
\hline Gonzáles, Floreal & 5 & $1,1 \%$ \\
\hline Roepke, Wilhelm & 4 & $0,9 \%$ \\
\hline Alberdi, Juan Bautista & 4 & $0,9 \%$ \\
\hline Harper, Floyd A. & 4 & $0,9 \%$ \\
\hline Reig Albiol, Jaoquín & 4 & $0,9 \%$ \\
\hline Benegas, Fernando & 4 & $0,9 \%$ \\
\hline Bastiat, Federico & 4 & $0,9 \%$ \\
\hline Chamberlain, John & 4 & $0,9 \%$ \\
\hline Curtiss, W.M. & 4 & $0,9 \%$ \\
\hline Ayau, Manuel F. & 4 & $0,9 \%$ \\
\hline Luzzetti, Carlos & 3 & $0,6 \%$ \\
\hline Nymeyer, Frederick & 3 & $0,6 \%$ \\
\hline Carca, Norberto Luis & 3 & $0,6 \%$ \\
\hline Petro, Sylvester & 3 & $0,6 \%$ \\
\hline Kemp, Arthur & 3 & $0,6 \%$ \\
\hline Sparks, John C. & 3 & $0,6 \%$ \\
\hline Sanchez Sañudo, Carlos A. & 3 & $0,6 \%$ \\
\hline Hospers, John & 3 & $0,6 \%$ \\
\hline Arathoon, Hilary & 3 & $0,6 \%$ \\
\hline Zanotti, Gabriel J. & 3 & $0,6 \%$ \\
\hline Linares Quintana, Segundo V & 3 & $0,6 \%$ \\
\hline Chodorov, Frank & 2 & $0,4 \%$ \\
\hline Pettengill, Samuel B. & 2 & $0,4 \%$ \\
\hline Ballvé, Faustino & 2 & $0,4 \%$ \\
\hline Lastra, Alejadro & 2 & $0,4 \%$ \\
\hline Rand, Any & 2 & $0,4 \%$ \\
\hline Velasco, Gustavo R. & 2 & $0,4 \%$ \\
\hline Fernández del Casal, Alberto & 2 & $0,4 \%$ \\
\hline Bien, Bettina & 2 & $0,4 \%$ \\
\hline Coleson, Edwars P. & 2 & $0,4 \%$ \\
\hline
\end{tabular}




\begin{tabular}{|c|c|c|}
\hline Luque, Rodolfo N. & 2 & $0,4 \%$ \\
\hline Smith, Harlan L. & 2 & $0,4 \%$ \\
\hline Optiz, Edmund A. (Reverendo) & 2 & $0,4 \%$ \\
\hline Shenoy, Sudha R. & 2 & $0,4 \%$ \\
\hline Elsom, Harold B. & 2 & $0,4 \%$ \\
\hline Rogge, Benjamín A. & 2 & $0,4 \%$ \\
\hline Loncán, Enrique J. & 2 & $0,4 \%$ \\
\hline Brandt, Karl & 2 & $0,4 \%$ \\
\hline Brodin, Eric & 2 & $0,4 \%$ \\
\hline Anderson, Robert G. & 2 & $0,4 \%$ \\
\hline Juárez-Paz, Rigoberto & 2 & $0,4 \%$ \\
\hline Tranquillius & 2 & $0,4 \%$ \\
\hline Wriston, Walter B. & 2 & $0,4 \%$ \\
\hline Cachanosky, Juan Carlos & 2 & $0,4 \%$ \\
\hline Greaves, Percy L. (h) & 2 & $0,4 \%$ \\
\hline Rodríguez Varela,Alberto & 2 & $0,4 \%$ \\
\hline Ball, Carlos A. & 2 & $0,4 \%$ \\
\hline Shelly, Thomas J. & 1 & $0,2 \%$ \\
\hline Echeverria, Esteban & 1 & $0,2 \%$ \\
\hline Amunategui, Miguel Luis & 1 & $0,2 \%$ \\
\hline Ibele, Oscar & 1 & $0,2 \%$ \\
\hline Hunold, Albert C. & 1 & $0,2 \%$ \\
\hline Padilla, Benedicto & 1 & $0,2 \%$ \\
\hline Ferrero, Rómulo A. & 1 & $0,2 \%$ \\
\hline Tolstoy, León N. & 1 & $0,2 \%$ \\
\hline Hoff, Trygve J. & 1 & $0,2 \%$ \\
\hline Jalón, Diego & 1 & $0,2 \%$ \\
\hline Shenfield, A. A. & 1 & $0,2 \%$ \\
\hline Van Sickle, John V. & 1 & $0,2 \%$ \\
\hline Branden, Bárbara & 1 & $0,2 \%$ \\
\hline Steele, Peter & 1 & $0,2 \%$ \\
\hline Yankus, Stanley & 1 & $0,2 \%$ \\
\hline Jebb, Reginald & 1 & $0,2 \%$ \\
\hline Armond, Fred de & 1 & $0,2 \%$ \\
\hline Hutton, E. F. & 1 & $0,2 \%$ \\
\hline Schuettinger, Robert & 1 & $0,2 \%$ \\
\hline Dobríansky, Lev E. & 1 & $0,2 \%$ \\
\hline Sullivan, Lawrence & 1 & $0,2 \%$ \\
\hline Molinelli, Nimar G. & 1 & $0,2 \%$ \\
\hline Burke, Edmund & 1 & $0,2 \%$ \\
\hline Fundación para estudios sobre la libertad. Bogota & 1 & $0,2 \%$ \\
\hline Shallcross Maynard, Ruth & 1 & $0,2 \%$ \\
\hline Greenfield, Edward W. & 1 & $0,2 \%$ \\
\hline Rougier, Louis & 1 & $0,2 \%$ \\
\hline Anderson, Maxwell & 1 & $0,2 \%$ \\
\hline Magni, Leonidas & 1 & $0,2 \%$ \\
\hline La Prensa (Diario- editorial) & 1 & $0,2 \%$ \\
\hline Barger, Melvin D. & 1 & $0,2 \%$ \\
\hline Lachaume, P. Lhoste & 1 & $0,2 \%$ \\
\hline Fox, Willard M. & 1 & $0,2 \%$ \\
\hline Margenau, Henry & 1 & $0,2 \%$ \\
\hline
\end{tabular}


De Büren, M. P. Disputas discursivas. Ideas sobre la libertad en los desembarcos iniciales del movimiento neoliberal en Argentina

\begin{tabular}{|c|c|c|}
\hline Mahaffy, Francis E. & 1 & $0,2 \%$ \\
\hline Emeny, Cliff S. & 1 & $0,2 \%$ \\
\hline Bancks, Dean & 1 & $0,2 \%$ \\
\hline Asociación vitivinícola argentina & 1 & $0,2 \%$ \\
\hline Corral, Alberto (Fundac de estudios sobre la libertad. Bogota & 1 & $0,2 \%$ \\
\hline Pinedo, Federico & 1 & $0,2 \%$ \\
\hline The Morgan Garanty Survey & 1 & $0,2 \%$ \\
\hline Heilperin, Michael A. & 1 & $0,2 \%$ \\
\hline Paton, W. A. & 1 & $0,2 \%$ \\
\hline Salinas Price, Hugo & 1 & $0,2 \%$ \\
\hline Fiske, John & 1 & $0,2 \%$ \\
\hline Sirito, Juan Andrés & 1 & $0,2 \%$ \\
\hline Industrias Asociadas de Misouri & 1 & $0,2 \%$ \\
\hline The American Economic Foundation & 1 & $0,2 \%$ \\
\hline Cross, Mallory & 1 & $0,2 \%$ \\
\hline Vinelli, Rodolfo J. W. & 1 & $0,2 \%$ \\
\hline Dykes, Charles & 1 & $0,2 \%$ \\
\hline Benegas Lynch, Alberto (nieto) & 1 & $0,2 \%$ \\
\hline Zimmermann, Eduardo & 1 & $0,2 \%$ \\
\hline Soljenitsin, Alejandro & 1 & $0,2 \%$ \\
\hline Manion, Clarence & 1 & $0,2 \%$ \\
\hline Turnbull, Charles & 1 & $0,2 \%$ \\
\hline Romero, Carolina & 1 & $0,2 \%$ \\
\hline Summers, Brian & 1 & $0,2 \%$ \\
\hline Pio XII & 1 & $0,2 \%$ \\
\hline Higgs, Robert & 1 & $0,2 \%$ \\
\hline Wiarda, Howard J. & 1 & $0,2 \%$ \\
\hline Beltrán, Lucas & 1 & $0,2 \%$ \\
\hline Boragina, Gabriel Jorge & 1 & $0,2 \%$ \\
\hline Gómez, Eleuterio & 1 & $0,2 \%$ \\
\hline Redd, Laurence W. & 1 & $0,2 \%$ \\
\hline von Kuehnelt-Leddihn, Erik & 1 & $0,2 \%$ \\
\hline Ribas, Armando P. & 1 & $0,2 \%$ \\
\hline Bechara, Dennis & 1 & $0,2 \%$ \\
\hline Ravines, Eudocio & 1 & $0,2 \%$ \\
\hline Rogers, James M. & 1 & $0,2 \%$ \\
\hline Berruti, Pedro & 1 & $0,2 \%$ \\
\hline Belgrano, Juan Manuel & 1 & $0,2 \%$ \\
\hline Vidal Molina, Enrique & 1 & $0,2 \%$ \\
\hline Madland, Lee G. & 1 & $0,2 \%$ \\
\hline Taft Benson, Ezra & 1 & $0,2 \%$ \\
\hline Cammarota, Aldo & 1 & $0,2 \%$ \\
\hline Santos Gollán, José & 1 & $0,2 \%$ \\
\hline Cucchetti, Carlos & 1 & $0,2 \%$ \\
\hline Malbrán, Manuel E. & 1 & $0,2 \%$ \\
\hline Sánchez Covisa, Joaquín & 1 & $0,2 \%$ \\
\hline Royster, Vermont & 1 & $0,2 \%$ \\
\hline Cooley, Oscar W. & 1 & $0,2 \%$ \\
\hline Autor anónimo & 1 & $0,2 \%$ \\
\hline Watts, V. Orval & 1 & $0,2 \%$ \\
\hline Braun, Armando M. & 1 & $0,2 \%$ \\
\hline
\end{tabular}


De Büren, M. P. Disputas discursivas. Ideas sobre la libertad en los desembarcos iniciales del movimiento neoliberal en Argentina

\begin{tabular}{|c|c|c|}
\hline Gallo, Ezequiel L. & 1 & $0,2 \%$ \\
\hline Brozen, Yale & 1 & $0,2 \%$ \\
\hline Alazraqui Alonso, Jaime M. & 1 & $0,2 \%$ \\
\hline Benegas Lynch, Marieta & 1 & $0,2 \%$ \\
\hline Arenz, Enrique & 1 & $0,2 \%$ \\
\hline Foss, Kendall & 1 & $0,2 \%$ \\
\hline Harcourt- Rivington, S. & 1 & $0,2 \%$ \\
\hline C.L. & 1 & $0,2 \%$ \\
\hline Salceda, Alberto C. & 1 & $0,2 \%$ \\
\hline Smith, Bradford B. & 1 & $0,2 \%$ \\
\hline Rothbard, Murray N. & 1 & $0,2 \%$ \\
\hline Leoni, Bruno & 1 & $0,2 \%$ \\
\hline Sargent, Lois H. & 1 & $0,2 \%$ \\
\hline Jurado, Alicia & 1 & $0,2 \%$ \\
\hline Frias Silva, Juan C. & 1 & $0,2 \%$ \\
\hline Venturi, Jorge L. García & 1 & $0,2 \%$ \\
\hline Stevens, Paul & 1 & $0,2 \%$ \\
\hline Mitre, Bartolomé & 1 & $0,2 \%$ \\
\hline Gainza Paz, Alberto & 1 & $0,2 \%$ \\
\hline Río, Manuel & 1 & $0,2 \%$ \\
\hline Peterson, Williams $\mathrm{H}$. & 1 & $0,2 \%$ \\
\hline Koether, George & 1 & $0,2 \%$ \\
\hline Rimido, Obsoleto P. & 1 & $0,2 \%$ \\
\hline Goodman Ch. & 1 & $0,2 \%$ \\
\hline Thomsen, Steve & 1 & $0,2 \%$ \\
\hline Ellis, Edwars S. & 1 & $0,2 \%$ \\
\hline de Gandía, Enrique & 1 & $0,2 \%$ \\
\hline Novak, Michael & 1 & $0,2 \%$ \\
\hline Domínguez Benavides, Alejandro & 1 & $0,2 \%$ \\
\hline Albornoz, Miguel & 1 & $0,2 \%$ \\
\hline Rueff, Jacques & 1 & $0,2 \%$ \\
\hline Gresham, Perry E. & 1 & $0,2 \%$ \\
\hline Sopeña, Germán & 1 & $0,2 \%$ \\
\hline Hessen, Robert & 1 & $0,2 \%$ \\
\hline Anderson, Gordon T. & 1 & $0,2 \%$ \\
\hline Pazos, Luis & 1 & $0,2 \%$ \\
\hline Isaacs,Mark D. & 1 & $0,2 \%$ \\
\hline Keller, Deborah & 1 & $0,2 \%$ \\
\hline Vargas Llosa, Mario & 1 & $0,2 \%$ \\
\hline Repetto, Roberto & 1 & $0,2 \%$ \\
\hline Salas Falcón, Fernando & 1 & $0,2 \%$ \\
\hline Zheng, Pujie & 1 & $0,2 \%$ \\
\hline Díaz Bessone, Ramón Genaro & 1 & $0,2 \%$ \\
\hline Bendfedt, Juan F. & 1 & $0,2 \%$ \\
\hline Total & 499 & \\
\hline Total sin contabilizar las notas editoriales & 464 & $100,0 \%$ \\
\hline
\end{tabular}

Fuente: Elaboración propia en base a información disponible en Ideas Sobre la Libertad N 1 a N 54. Diciembre de 1958-Diciembre de 1989. 
Encabeza la lista de publicaciones - junto al fundador del CDEL- Leonard Read quien ha sido gerente general de la rama Los Ángeles de la Cámara de Comercio de los Estados Unidos (1939); vicepresidente de la National Industrial Conference Board de Nueva York (1945); fundador de la Foundation for Economic Education (FEE) (1946, Nueva York). Institución, esta última, que gozó del apoyo financiero de William Volker Found y Harold Luhnow; que se encarga de la edición de la Revista The Freeman lectura de cabecera de Ronald Reagan- y que se ha constituido en un centro de producción y difusión discursiva del movimiento monpelerines. En tal fundación dictaban clases sus máximos referentes, acudían a capacitarse estudiantes de Argentina y del resto de América Latina, quienes producían escritos que luego eran reproducidos en sus propias revistas y en las revistas de toda la red mundial. Para la primera reunión de Mont Pèlerin Society, Hayek solicitó a Leonard Read la organización del contingente norteamericano (Hartwell, 1995, de Büren ,2015; de Büren, 2020, de Büren, 2019).

Read da la bienvenida a la revista argentina Ideas Sobre la Libertad (ISL) en su calidad de dispositivo de difusión mediante el envió de una elogiosa carta que fue publicada en su número inicial. A partir de allí ISL, entre otras prácticas, re-publica artículos inicialmente presentados en los Estados Unidos en la revista The Freeman que el propio Read edita. Este personaje ha brindado conferencias en nuestro país en junio de 1977 en las instalaciones de la Escuela Superior de Guerra y el Comando en jefe de la Armada Nacional (de Büren, 2014). Entre sus numerosos artículos publicados en ISL podríamos destacar: "Dos maneras de evitar las huelgas", "Combatir el Estatismo", "Como reducir los impuestos", "El caso en defensa del mercado libre en la educación", "El hombre de la masa", "El milagro del mercado", "Las empresas tienen 'derecho' a una ganancia justa", "Shylock (usurero) iCobra cuanto puede!", "Sobre la libertad y el orden" (ISL N¹, 2, 6, 21, 3, 9, 16, 17, 23).

En igual preeminencia aparecen los trabajos del presidente del CDEL, Alberto Benegas Lynch. Este personaje es quien se encarga de entablar relaciones en los Estados Unidos, en las instalaciones de la Universidad de Chicago con Friedrich Hayek -el entonces presidente y fundador de Mont Pèlerin Society- en el año 1950, a partir de ello funda el CDEL destinado a difundir el ideario montpelerines en suelo argentino al igual que, para la misma época, lo hacen otras instituciones en el resto de América Latina y el mundo (Hartwell, 1995; de Büren, 2020; de Büren, 2020a; de Büren, 2015). Según reza el homenaje que le brindase el periódico La Nación en ocasión de su fallecimiento, este político, empresario y académico presidió la empresa vitivinícola que su abuelo fundase en 1883, fue presidente de la Asociación Vitivinícola Argentina y de la Cámara Argentina de Comercio; fue miembro de la Academia Nacional de Ciencias Económicas, de la Academia Nacional de Ciencias Morales y Políticas y de la Academia Nacional de Economía del Uruguay. A través del Centro de Estudios sobre la Libertad, invitó a la Argentina a, entre otros, Friedrich Hayek y Ludwig von Mises y ofreció becas a argentinos en los Estados Unidos con objeto de que ahondaran en el estudio del mercado libre. Durante los dos primeros años de la Revolución Libertadora vivió en Washintong, donde fue ministro plenipotenciario de la embajada argentina. ( $L a$ Nación, 20 de febrero de 1999). Entre los artículos que publicó en ISL destacamos "Eficacia anticomunista", "La propiedad: imprescindible factor progreso", "La 
subversión institucional", "Tierra y propiedad", "Trabajo libre: fuente de prosperidad obrera" (ISL No 14, 17, 49, 82, 4).

Continúan la lista los artículos de Hans Sennholz quien se formase con Ludwig von Mises y fundase el Grove City College, instituto norteamericano de propósitos similares a la Foundation for Economics Education, y Alberto Benegas Lynch (h), hijo del fundador y presidente del CDEL y creador -con ayuda de fondos provistos por miembros de la Bolsa de Comercio de Buenos Aires- de la Escuela de Administración y Economía (ESEADE). Institución de posgrado fundada en 1977 con objeto de continuar la labor del CDEL pero ahora ofreciendo, además, titulaciones de posgrado (de Büren, 2019; de Büren, 2020a; de Büren, 2014; Benegas Lynch (h), 2007). Entre diciembre de 1958 y diciembre de 1989, Ideas Sobre la Libertad publica, entre otros, "El fantasma llamado 'monopolion", "El mito del colonialismo capitalista", "Sindicalismo destructor de los principios de la economía de mercado" de Hans Sennholz (ISL N 6, 4, 52) y "Cuatro décadas de estatismo en Latinoamérica", "Descentralización industrial y despilfarro de capital", "Imposibilidad de cálculo económico en el sistema socialista", "Un ejemplo del absurdo: el caso de las empresas estatales" de Alberto Benegas Lynch (h) (ISL $N^{\circ} 39$, $33,27,47$ ).

Prosiguen en orden de importancia numérica, artículos inspirados en los referentes mundiales de la Escuela Austriaca de Economía Ludwig von Mises, Henry Hazlitt y Friedrich Hayek, a los que podríamos agregar -a pesar de su menor peso relativo- las publicaciones de otras destacas figuras de dicha perspectiva de pensamiento: Sylvester Petro y Murray Rothbard. Entre los artículos de estos autores que ISL reproduce destacamos "El individuo en la sociedad" -fragmento de su obra La Acción Humana-, "Fracaso Económico del sistema soviético", "Libertad y Propiedad" de Ludwig von Mises (ISL No 29, 4, 2); " 'Moneda' internacional", "Cómo los sindicatos reducen los salarios reales" -fragmento de su obra La conquista de la pobreza, "Indexación: Una salida equivocada", "Las obras públicas incrementan las cargas fiscales" de Henry Hazlitt (ISL № 10, 31, 36 ); "El elemento de la empresa libre", "La planificación y el Estado de Derecho" y "Renacimiento del Liberalismo" de Friedrich von Hayek (ISL No 12, 52, 1 ); y "El peligro del poder sindical" de Sylvester Petro (ISL $N^{\circ} 5$ ). Cabe destacar que los autores antes mencionados -Alberto Benegas Lynch, padre e hijo, y Hans Sennholztambién constituyen autores formados y adscriptos a la Escuela Austriaca de Economía, lo cual, hace que el lineamiento de esta publicación este fuerte y mayoritariamente guiada por esta corriente de pensamiento.

\subsection{Procedencia institucional de los autores}

En este momento del análisis de los autores reproducidos en Ideas Sobre la Libertad se hace pertinente su agrupación en función de la procedencia institucional a fin de observar lo que Michel Foucault denomina la "posición de sujeto" desde las cuales son pronunciados los enunciados que aquí se difunden, la articulación institucional que constituye su base material de emergencia y soporte y las vinculaciones internacionales que contribuyen a su aparición y circulación. 
De Büren, M. P. Disputas discursivas. Ideas sobre la libertad en los desembarcos iniciales del movimiento neoliberal en Argentina

En base a información que ha sido declarada por la misma revista Ideas Sobre la Libertad en su publicación de cada artículo, se ha elaborado la Tabla 2- disponible a continuación- que releva la procedencia institucional de su autor. El peso relativo otorgado a cada institución está significado por la cantidad de artículos publicados de autores pertenecientes a la misma, siempre y cuando, haya sido informado en el artículo publicado en Ideas Sobre la Libertad"

Tabla 2. Procedencia institucional de autores. Frecuencia de aparición. Diciembre de 1958-diciembre de 1989.ISL N¹ a No54

\begin{tabular}{|c|c|c|}
\hline Institución & Frecuencia & Porcentaje \\
\hline The Foundation for Economic Education (FEE) & 33 & $17,1 \%$ \\
\hline Centro de Difusión de la Economía Libre (CDEL) & 27 & $14,0 \%$ \\
\hline Grove City College & 16 & $8,3 \%$ \\
\hline Universidad de Chicago & 5 & $2,6 \%$ \\
\hline Universidad de Nueva York & 5 & $2,6 \%$ \\
\hline Universidad Francisco de Marroquín & 5 & $2,6 \%$ \\
\hline Mont Pèlerin Society & 4 & $2,1 \%$ \\
\hline Wall Street Journal & 4 & $2,1 \%$ \\
\hline Human Events & 3 & $1,6 \%$ \\
\hline Rockford College & 3 & $1,6 \%$ \\
\hline Wabash College & 3 & $1,6 \%$ \\
\hline American Enterprise Institute & 2 & $1,0 \%$ \\
\hline Baron's y Newsweek & 2 & $1,0 \%$ \\
\hline Cámara de Comercio y Empresas Comerciales de Perú & 2 & $1,0 \%$ \\
\hline Campbell College & 2 & $1,0 \%$ \\
\hline Colegio de Abogados de Buenos Aires & 2 & $1,0 \%$ \\
\hline Diario Caracas & 2 & $1,0 \%$ \\
\hline New York Times & 2 & $1,0 \%$ \\
\hline Stanford University, Hoover Institution & 2 & $1,0 \%$ \\
\hline Suprema Corte, Nueva Zelanda & 2 & $1,0 \%$ \\
\hline Universidad de California del Sur & 2 & $1,0 \%$ \\
\hline Universidad de Stanford & 2 & $1,0 \%$ \\
\hline William Volker Fund & 2 & $1,0 \%$ \\
\hline Academia Nacional de Ciencias Morales y Políticas. & 1 & $0,5 \%$ \\
\hline Academia Nacional de Ciencias Económicas & 1 & $0,5 \%$ \\
\hline American Institute for Economic Research & 1 & $0,5 \%$ \\
\hline American Society for Aesthetics & 1 & $0,5 \%$ \\
\hline
\end{tabular}

${ }^{4}$ Como en el análisis de la tabla anterior, los datos presentados se remiten a los "artículos" presentes en Ideas Sobre la Libertad $N^{\circ} 1$ a N 54, es decir, desde diciembre de 1958 a diciembre de 1989. Sólo son relevados los "artículos" presentes en las mismas, quedan afuera de la población de análisis fragmentos de escritos presentados en otra modalidad. También es necesario remarcar que el número total final excede al número de artículos del periodo ya que la procedencia institucional no siempre es única, en determinadas oportunidades, la revista presenta varias filiaciones para el autor de un artículo. Los datos aquí vertidos son extraídos de la información presentada en la revista Ideas Sobre la Libertad en cada artículo procesado, por ello, el lector puede observar, por ejemplo, escasa relación a Mont Pèlerin Society. Lo cual se debe a que se han contabilizado sólo aquellas filiaciones que son expresadas en el artículo de la revista 
De Büren, M. P. Disputas discursivas. Ideas sobre la libertad en los desembarcos iniciales del movimiento neoliberal en Argentina

\begin{tabular}{|c|c|c|}
\hline Aristotelican Society & 1 & $0,5 \%$ \\
\hline Banco & 1 & $0,5 \%$ \\
\hline Cámara Argentina de Comercio & 1 & $0,5 \%$ \\
\hline Cámara Argentina de la Construcción & 1 & $0,5 \%$ \\
\hline Cámara de los Representantes de los EE UU & 1 & $0,5 \%$ \\
\hline Cámara Federal de Apelaciones, La Plata. & 1 & $0,5 \%$ \\
\hline Centro de Estudios Económico-Sociales & 1 & $0,5 \%$ \\
\hline Centro de Investigaciones de la Libre Empresa & 1 & $0,5 \%$ \\
\hline Claremont Men's College. & 1 & $0,5 \%$ \\
\hline Coloquio Walter Lippmann & 1 & $0,5 \%$ \\
\hline Congreso de la Nación, Filipinas & 1 & $0,5 \%$ \\
\hline Cortes de España & 1 & $0,5 \%$ \\
\hline Delegación de los EEUU en la Comisión de DDHH de ONU & 1 & $0,5 \%$ \\
\hline E. F. Hutton \& Co. & 1 & $0,5 \%$ \\
\hline London School of Economics (LSE) & 1 & $0,5 \%$ \\
\hline Escuela Libre de Derecho & 1 & $0,5 \%$ \\
\hline ESEADE & 1 & $0,5 \%$ \\
\hline Farmand & 1 & $0,5 \%$ \\
\hline Federación de Industrias Británicas & 1 & $0,5 \%$ \\
\hline First National City Bank of New York & 1 & $0,5 \%$ \\
\hline First Principles in Morality and Economics. & 1 & $0,5 \%$ \\
\hline Huntintog College & 1 & $0,5 \%$ \\
\hline Iglesia Católica & 1 & $0,5 \%$ \\
\hline Instituto de Investigaciones Sociales y Económicas & 1 & $0,5 \%$ \\
\hline Instituto Suizo de Estudios Internacionales & 1 & $0,5 \%$ \\
\hline Intercollegiate Society of individualist & 1 & $0,5 \%$ \\
\hline James U. Blanchard \& Company & 1 & $0,5 \%$ \\
\hline La Prensa. & 1 & $0,5 \%$ \\
\hline Lake Erie College & 1 & $0,5 \%$ \\
\hline Le Point de Rencontre Liberal-Spiritualiste & 1 & $0,5 \%$ \\
\hline New Individualist Review & 1 & $0,5 \%$ \\
\hline Northwood Institute & 1 & $0,5 \%$ \\
\hline Partido Liberal Libertario de EEUU & 1 & $0,5 \%$ \\
\hline Royal Institute of Philosophy & 1 & $0,5 \%$ \\
\hline $\begin{array}{l}\text { Seminario de la Santa Cruz, Universidad Gregoriana de Roma y } \\
\text { Stonehill College }\end{array}$ & 1 & $0,5 \%$ \\
\hline Seminario (No sé si católico) & 1 & $0,5 \%$ \\
\hline Sociedad Pro Empresa Libre & 1 & $0,5 \%$ \\
\hline Spring Harbor College & 1 & $0,5 \%$ \\
\hline The Flying $A$ & 1 & $0,5 \%$ \\
\hline The Mackinac Center & 1 & $0,5 \%$ \\
\hline The Monist & 1 & $0,5 \%$ \\
\hline The Morgan Garanty Survey & 1 & $0,5 \%$ \\
\hline The Objectivist Newsletter & 1 & $0,5 \%$ \\
\hline Think it through & 1 & $0,5 \%$ \\
\hline UBA. Fac. de Cs Económicas & 1 & $0,5 \%$ \\
\hline Universidad de Bethany & 1 & $0,5 \%$ \\
\hline Universidad de Bue's Greek & 1 & $0,5 \%$ \\
\hline Universidad de Georgentown & 1 & $0,5 \%$ \\
\hline Universidad de Gujarat & 1 & $0,5 \%$ \\
\hline
\end{tabular}


De Büren, M. P. Disputas discursivas. Ideas sobre la libertad en los desembarcos iniciales del movimiento neoliberal en Argentina

\begin{tabular}{|c|c|c|}
\hline Universidad de Masachussettes & 1 & $0,5 \%$ \\
\hline Universidad de Michigan & 1 & $0,5 \%$ \\
\hline Universidad de Tennessee & 1 & $0,5 \%$ \\
\hline Universidad de Washintong & 1 & $0,5 \%$ \\
\hline Universidad de Yale & 1 & $0,5 \%$ \\
\hline Universidad del Museo Social Argentino & 1 & $0,5 \%$ \\
\hline Universidad de Oklahoma & 1 & $0,5 \%$ \\
\hline Universidad Estadual de Kent & 1 & $0,5 \%$ \\
\hline Total & 193 & $100 \%$ \\
\hline
\end{tabular}

Fuente: Elaboración propia en base a Ideas Sobre la Libertad №1 a ํ54.

La Tabla 2 nos permite observar que la mayoría de los artículos publicados en ISL entre diciembre de 1958 y diciembre de 1989, es decir, entre sus números 1 a 54, provienen, en primer lugar, de autores vinculados a la institución que dirige Leonard Read, The Foundatión for Economic Education, -ellos alcanzan el 17,1\% -; en segundo -en un 14\%-, de la que preside Alberto Benegas Lynch, el Centro de Difusión de la Economía Libre (CDEL)-; luego -en un 8,3\%- de la Universidad donde desempeña sus actividades Hans Sennholz, el Grove City College; a continuación -en un 2,6\%- de la Universidad de Chicago donde es notable la figura del montpelerines Milton Friedman, de la Universidad de Nueva York donde Ludwig von Mises se desempeña como docente y de la Universidad Francisco de Marroquín fundada y dirigida por uno de los pocos latinoamericanos que han ejercido la presidencia de Mont Pèlerin Society, Manual Ayau; posteriormente -en un 2,1\%- de Mont Pèlerin Society ${ }^{5}$ y del Wall Street Journal.

Entre los artículos publicados en Ideas Sobre la Libertad de autores vinculados a la Foundation for Economic Education y a cualquiera de sus dependencias- la revista The Freeman y su Escuela de Economía Política- encontramos algunos de los textos anteriormente mencionados de Henry Hazlitt, Leonard Read y Ludwig von Mises y podríamos destacar "La libertad sigue al mercado libre" de Dean Russell y "Liberalismo solía significar libertad" del Reverendo Edmund A. Optiz (ISL N 17, 38).

Los trabajos publicados de autores afiliados al CDEL incluye algunos de los textos citados de Alberto Benegas Lynch, Alberto Benegas Lynch (h) y Fernando Benegas y otros, entre los que sobresalen, "Tendencias antiliberales de la democracia en América Latina" de Manuel Tagle y "Para la Biblioteca del Hombre Liberal" -comentario de La Acción Humana de von Mises cuando su traducción al español acaba de aparecer- de Carlos Luzzetti. (ISL N³, 7).

Los artículos reproducidos en Ideas Sobre la Libertad entre diciembre de 1958 y diciembre de 1989 de autores asociados a Grove City College incluyen algunos de los mencionados de Hans F. Sennholz y otros, entre los que se destacan, "El renacimiento de la libertad" de Clarence B. Carson (ISL $N^{\circ} 17$ ). De autores vinculados

${ }^{5}$ Corresponde la explicación vertida en el pie de página anterior. No son relevados todos los autores vinculados a Mont Pèlerin Society ya que se registran sólo los declarados por ISL y sólo en los artículos declarados. 
De Büren, M. P. Disputas discursivas. Ideas sobre la libertad en los desembarcos iniciales del movimiento neoliberal en Argentina

a la Universidad Francisco de Marroquín destacamos el artículo "El racionamiento en la economía de mercado libre" de Manuel F. Ayau (ISL No 47). Finalmente, resaltamos de autores de Mont Pèlerin Society "Esta época de 'ne laissez pas faire" de Albert C. Hunold, (ISL No 4) y de escritores filiados al Wall Street Journal "El comunismo no es una ola de futuro"de William Henry Chamberlin (ISL No 13).

\subsection{Carácter de los centros de difusión de origen de los autores}

La Tabla 3 - disponible a continuación- clasifica ${ }^{6}$ las instituciones que ya fueron presentadas en la Tabla $\mathbf{2}$ de forma desagregada y las reúne en distintas categorías, exhibe por fuera de tal catalogación el Centro de Estudios Sobre la Libertad (CDEL), al Grove City College y a la Foundation for Economic Education (FEE) debido su relevancia relativa y a Mont Pèlerin Society y al Coloquio Walter Lippmann, en tanto instancias de organización global del movimiento7.

Tabla 3: Autores de ISL. Procedencia Institucional Clasificada. Frecuencia de aparición. Diciembre de 1958- Diciembre de 1989. ISL No1 a No54

\begin{tabular}{|c|c|c|c|c|}
\hline $\begin{array}{c}\text { Tipo de } \\
\text { Institución }\end{array}$ & Institución & \multicolumn{2}{|c|}{ Cantidad } & Porcentaje \\
\hline \multirow{9}{*}{ Universidades } & Universidad de Chicago, EEUU. & 5 & \multirow{9}{*}{47} & \multirow{9}{*}{$24 \%$} \\
\hline & Universidad de Nueva York, EEUU & 5 & & \\
\hline & $\begin{array}{l}\text { Universidad Francisco de Marroquín, } \\
\text { Guatemala }\end{array}$ & 5 & & \\
\hline & Rockford College, EEUU & 3 & & \\
\hline & $\begin{array}{c}\text { Wabash College, Crawfordsville, } \\
\text { Indiana, EEUU }\end{array}$ & 3 & & \\
\hline & $\begin{array}{c}\text { Campbell College, Carolina del Norte, } \\
\text { EEUU. }\end{array}$ & 2 & & \\
\hline & $\begin{array}{l}\text { Hoover Institution, Stanford } \\
\text { University, EEUU. }\end{array}$ & 2 & & \\
\hline & Universidad de Stanford & 2 & & \\
\hline & $\begin{array}{c}\text { Claremont Men's College; Claremont, } \\
\text { California, EEUU }\end{array}$ & 1 & & \\
\hline
\end{tabular}

${ }^{6}$ Esta clasificación de ningún modo cumple los requisitos de exhaustividad colectiva y exclusión individual. Cada una de las instituciones podrían clasificarse en más de una de las categorías propuestas, las cuales se presentan a modo de estrategia analítica.

${ }^{7}$ Como se aclaró en nota al pie precedente, la escasa relevancia de la participación de Mont Pèlerin Society no se explica por baja filiación real de los autores de Ideas Sobre la Libertad a la misma, sino porque las tablas 2 y 3 sólo relevan la información expresada en los artículos.

${ }^{8}$ La Universidad Francisco de Marroquín fue fundada por Manuel Ayau. Este guatemalteco, único latinoamericano que ocupó en alguna ocasión la presidencia de Mont Pèlerin Society, ha organizado y dirigido el par del argentino CDEL, el Centro de Estudios Sociales y Económicos, (Benegas Lynch en N³8, diciembre de 1979, Benegas Lynch en ISL N³9, septiembre de 1980, Harwell,1995) 
De Büren, M. P. Disputas discursivas. Ideas sobre la libertad en los desembarcos iniciales del movimiento neoliberal en Argentina

\begin{tabular}{|c|c|c|c|c|}
\hline & $\begin{array}{l}\text { London School of Economics (LSE), } \\
\text { Inglaterra. }{ }^{9}\end{array}$ & 1 & & \\
\hline & Huntintog College & 1 & & \\
\hline & $\begin{array}{c}\text { Lake Erie College, Painesville, Ohío, } \\
\text { EEUU }\end{array}$ & 1 & & \\
\hline & Spring Harbor College & 1 & & \\
\hline & $\begin{array}{c}\text { Fac. de Ciencias Económicas, } \\
\text { Universidad de Buenos Aires, Argentina }\end{array}$ & 1 & & \\
\hline & $\begin{array}{c}\text { Universidad de Bethany, West Virginia, } \\
\text { EEUU }\end{array}$ & 1 & & \\
\hline & $\begin{array}{c}\text { Universidad de Bue's Greek, Carolina } \\
\text { del Norte, EEUU. }\end{array}$ & 1 & & \\
\hline & $\begin{array}{c}\text { Universidad de California del Sur, Los } \\
\text { Angeles, EEUU. }\end{array}$ & 2 & & \\
\hline & Universidad de Georgentown & 1 & & \\
\hline & $\begin{array}{l}\text { Universidad de Gujarat, Ahmedabad, } \\
\text { India }\end{array}$ & 1 & & \\
\hline & \begin{tabular}{|c|} 
Depto. de Cs. Políticas, Universidad de \\
Masachussettes,EEUU.
\end{tabular} & 1 & & \\
\hline & Universidad de Michigan, EEUU. & 1 & & \\
\hline & $\begin{array}{l}\text { Centro de Educación Económica, } \\
\text { Universidad de Tennessee, EEUU }\end{array}$ & 1 & & \\
\hline & Universidad de Washintong & 1 & & \\
\hline & Universidad de Yale & 1 & & \\
\hline & $\begin{array}{l}\text { Universidad del Museo Social } \\
\text { Argentino, Argentina }\end{array}$ & 1 & & \\
\hline & Universidad de Oklahoma & 1 & & \\
\hline & Universidad Estadual de Kent & 1 & & \\
\hline FEE & $\begin{array}{l}\text { The Foundatión for Economic } \\
\text { Education, New York. }\end{array}$ & 33 & 33 & $17 \%$ \\
\hline CDEL & $\begin{array}{c}\text { Centro de Difusión de la Economía } \\
\text { Libre Argentina }\end{array}$ & 27 & 27 & $14 \%$ \\
\hline Grove City College & Grove City College, Pensilvania, EEUU. & 16 & 16 & $8 \%$ \\
\hline \multirow{8}{*}{$\begin{array}{c}\text { Instituciones } \\
\text { empresariales } \\
\text { (Empresas o } \\
\text { agrupaciones } \\
\text { empresaria) }\end{array}$} & $\begin{array}{c}\text { Cámara de Comercio y Empresas } \\
\text { Comerciales, Perú. }\end{array}$ & 2 & \multirow{8}{*}{11} & \multirow{8}{*}{$6 \%$} \\
\hline & Banco -sin especificación-. & 1 & & \\
\hline & Cámara Argentina de Comercio & 1 & & \\
\hline & Cámara Argentina de la Construcción & 1 & & \\
\hline & E. F. Hutton \& Co. ${ }^{10}$ & 1 & & \\
\hline & Federación de Industrias Británicas & 1 & & \\
\hline & First National City Bank of New York & 1 & & \\
\hline & $\begin{array}{l}\text { James U. Blanchard \& Company, New } \\
\text { Orleans, Lousiana. }\end{array}$ & 1 & & \\
\hline
\end{tabular}

${ }^{9}$ Se puede conocer su historia visitando su web: http://www.lse.ac.uk/aboutLSE/aboutHome.aspx. Friedrich von Hayek desempeñó actividades en este centro gracias a la invitación de Lionel Robbins antes de emigrar a los EEUU. Espacio donde se enfrentó al keynesianismo presente en la institución. ${ }^{10}$ Sitio Web oficial: http://www.efhuttoncompany.com/ 
De Büren, M. P. Disputas discursivas. Ideas sobre la libertad en los desembarcos iniciales del movimiento neoliberal en Argentina

\begin{tabular}{|c|c|c|c|c|}
\hline & $\begin{array}{l}\text { The Flying A. Revista de Aeroquip } \\
\text { Corporation. En Jackson,Michigan }\end{array}$ & 1 & & \\
\hline & The Morgan Garanty Survey ${ }^{11}$ & 1 & & \\
\hline \multirow{5}{*}{ Periódicos } & Wall Street Journal & 4 & \multirow{5}{*}{10} & \multirow{5}{*}{$5 \%$} \\
\hline & Diario Caracas & 2 & & \\
\hline & New York Times & 2 & & \\
\hline & La Prensa, Buenos Aires, Argentina. & 1 & & \\
\hline & $\begin{array}{l}\text { Think it Through - Columna } \\
\text { periodística no especificada-. }\end{array}$ & 1 & & \\
\hline \multirow{5}{*}{ Revistas } & Human Events, EEUU. & 3 & \multirow{5}{*}{8} & \multirow{5}{*}{$4 \%$} \\
\hline & Baron's y Newsweek, EEUU. & 2 & & \\
\hline & $\begin{array}{c}\text { New Individualist Review, Chicago, } \\
\text { EEUU. }\end{array}$ & 1 & & \\
\hline & The Monist - Revista de Filosofía-. & 1 & & \\
\hline & $\begin{array}{c}\text { The Objectivist Newsletter -publicación } \\
\text { dirigida por Any Rand-. }\end{array}$ & 1 & & \\
\hline \multirow{6}{*}{$\begin{array}{c}\text { Organismos } \\
\text { Públicos- Estatales }\end{array}$} & Suprema Corte, Nueva Zelanda & 2 & \multirow{6}{*}{7} & \multirow{6}{*}{$4 \%$} \\
\hline & Cámara de los Representantes, EEUU. & 1 & & \\
\hline & $\begin{array}{l}\text { Cámara Federal de Apelaciones de La } \\
\text { Plata, Argentina. }\end{array}$ & 1 & & \\
\hline & Congreso de la Nación, Filipinas & 1 & & \\
\hline & Cortes de España & 1 & & \\
\hline & $\begin{array}{c}\text { Delegación norteamericana en la } \\
\text { Comisión de DDHH de ONU bajo } \\
\text { presidencia de R. Reagan }\end{array}$ & 1 & & \\
\hline \multirow{5}{*}{$\begin{array}{l}\text { Institutos de } \\
\text { Investigación }\end{array}$} & American Enterprise Institute & 2 & \multirow{5}{*}{6} & \multirow{5}{*}{$3 \%$} \\
\hline & $\begin{array}{l}\text { American Institute for Economic } \\
\text { Reaseach, Great Barrintong, } \\
\text { Massachusetts, EEUU. }\end{array}$ & 1 & & \\
\hline & $\begin{array}{l}\text { Instituto Suizo de Estudios } \\
\text { Internacionales }\end{array}$ & 1 & & \\
\hline & $\begin{array}{c}\text { Intercollegiate Society of Individualist, } \\
\text { Filadelfia }\end{array}$ & 1 & & \\
\hline & Northwood Institute, Michigan & 1 & & \\
\hline \multirow{3}{*}{ Think Tanks } & William Volker Fund, California. & 2 & \multirow{3}{*}{6} & \multirow{3}{*}{$3 \%$} \\
\hline & $\begin{array}{l}\text { First Principles in Morality and } \\
\text { Economics. Publicación de Libertarian } \\
\text { Press, South Holland, Illinois, EEUU }\end{array}$ & 1 & & \\
\hline & $\begin{array}{l}\text { Le Point de Rencontre Liberal- } \\
\text { Spiritualiste }{ }^{13}\end{array}$ & 1 & & \\
\hline
\end{tabular}

11 The Morgan Guaranty Survey"es una publicación periódica de la corporación empresaria "Morgan Guaranty Trust Company" de New York, EEUU.

${ }^{12}$ Se puede consultar la historia "Libertarian Press" fundado en 1952 por Fredrick Nymeyer con objeto de difundir el pensamiento de la Escuela Austríaca de Economía en su sitio web: http://www.libertarianpress.com/aboutus.php

${ }^{13}$ Le Point de Rencontre Liberal-Spiritualiste : "Agrupación de Estudios y Difusión Económicos y Sociales, fundada en 1947 que promueve propósitos de libertad en Francia en nuestros días." (ISL N 18, 1964, p. 30). 
De Büren, M. P. Disputas discursivas. Ideas sobre la libertad en los desembarcos iniciales del movimiento neoliberal en Argentina

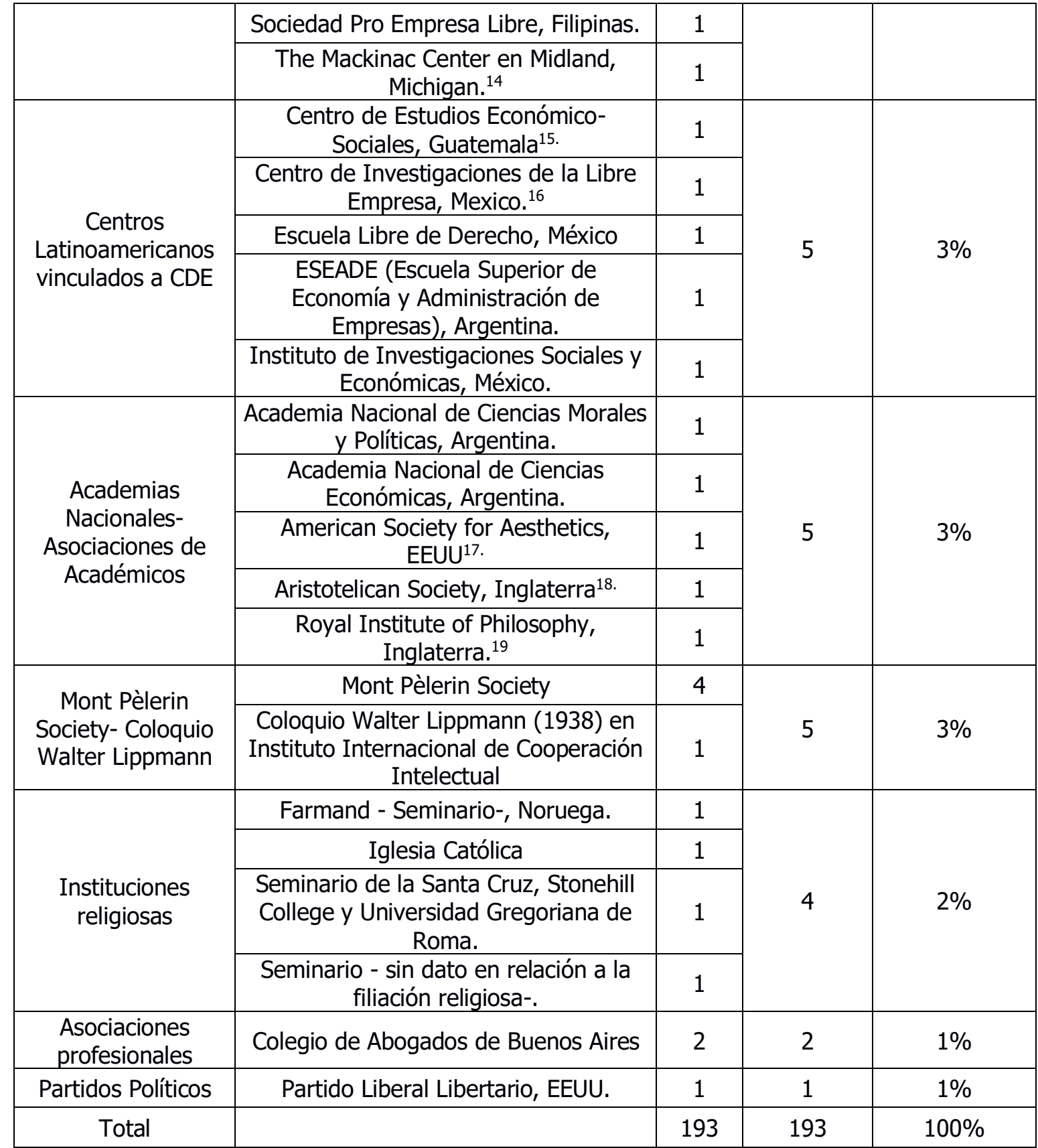

14 Tanque de pensamiento estadounidense promotor de la libre empresa. Para profundizar en su conocimiento consultar su sitio web en http://www.mackinac.org/1662

${ }^{15}$ Este par guatemalteco del CDEL fue fundado por Manuel Ayau, uno de los pocos latinoamericanos que ocupó en alguna ocasión la presidencia de Mont Pèlerin Society, es quien, además, ha organizado y dirigido la Universidad Francisco de Marroquín, (Benegas Lynch en №38, diciembre de 1979, Benegas Lynch en ISL N³9, septiembre de 1980, Hartwell,1995). Este centro editó, al menos, dos publicaciones periódicas "Tópicos de Actualidad" y "Hoja de Información Económica" (Juarez Paz en ISL №36, septiembre de 1978; Arathoon en ISL № 49, diciembre de 1986)

${ }_{16}$ Dirigido por Luis Pazos. Su sitio web se puede visitar en : http://www.cisle.org.mx/

${ }^{17}$ Su página oficial puede ser visitada en http://www.aesthetics-online.org/

${ }^{18}$ Su página oficial puede ser visitada en http://www.aristoteliansociety.org.uk/

19 Se puede consultar su historia, objetivos y actividades en su sitio web: http://www.royalinstitutephilosophy.org/page/41 
De Büren, M. P. Disputas discursivas. Ideas sobre la libertad en los desembarcos iniciales del movimiento neoliberal en Argentina

Fuente: Elaboración propia en base a Ideas Sobre la Libertad $N^{\circ} 1$ a Nº 54.

La Tabla 3 nos permite observar que tales trabajos eran escritos en un $24 \%$ por personas institucionalmente vinculadas a Universidades, en un $17 \%$ a la Fountation for Economic Education (FFE) -que bien podría ser agregada al conglomerado de Think Tanks-, en un $14 \%$ al CDEL, en un $8 \%$ al Grove City College; en un $6 \%$ a instituciones empresariales, sean ellas empresas o asociaciones empresarias; en un $5 \%$ a periódicos, en un $4 \%$ a revistas, en un $4 \%$ a organismos públicos o estatales, en un $3 \%$ a Institutos de Investigación, en un 3\% a Think Tanks no latinoamericanos con manifiesta identificación teórico ideológica, en un 3\% a Centros de difusiones pares del argentino CDEL, en un 3\% a Academias Nacionales o asociaciones de académicos, en un $3 \%$ a las organizaciones madre, Mont Pèlerin Society y el Coloquio Walter Lippmann; en un $2 \%$ a Instituciones religiosas y en un $1 \%$, respectivamente, a Asociaciones profesionales y Partidos Políticos.

\subsection{Posición de sujeto}

Finalmente presentamos en la Tabla 4 -disponible continuación- los cargos desempeñados por los autores reproducidos en Ideas Sobre la Libertad entre diciembre de 1958 y diciembre de 1989 en las instituciones antes reseñadas, a fin de observar, su potencial influencia ${ }^{20}$.

Tabla 4: Autores de ISL. Cargos desempeñados en su filiación institucional. Frecuencia de aparición. Diciembre de 1958- diciembre de 1989. ISL No1 a No54

\begin{tabular}{|c|c|c|}
\hline Cargo & Total (1) & Porcentaje \\
\hline Profesor & 46 & $22,9 \%$ \\
\hline Presidente & 31 & $15,4 \%$ \\
\hline Director & 19 & $9,5 \%$ \\
\hline Miembro & 17 & $8,5 \%$ \\
\hline Periodista & 10 & $5,0 \%$ \\
\hline Estudiante & 8 & $4,0 \%$ \\
\hline Investigador & 5 & $2,5 \%$ \\
\hline del equipo de redacción & 5 & $2,5 \%$ \\
\hline Mocal del Consejo de Administración & 5 & $2,5 \%$ \\
\hline Asesor & 4 & $2,0 \%$ \\
\hline Colaborador & 4 & $2,0 \%$ \\
\hline Decano & 4 & $2,0 \%$ \\
\hline Vicepresidente & 4 & $2,0 \%$ \\
\hline Empresario & 3 & $1,5 \%$ \\
\hline Rector & 3 & $1,5 \%$ \\
\hline
\end{tabular}

${ }^{20}$ Cómo en los casos anteriores la información se releva de Ideas sobre la Libertad, por tanto, los cargos aquí informados son los allí mencionados y el peso relativo otorgado está en función de los artículos en los que se hace presente. 
De Büren, M. P. Disputas discursivas. Ideas sobre la libertad en los desembarcos iniciales del movimiento neoliberal en Argentina

\begin{tabular}{|c|c|c|}
\hline Afiliado & 2 & $1,0 \%$ \\
\hline Co director & 2 & $1,0 \%$ \\
\hline Editor & 2 & $1,0 \%$ \\
\hline Miembro Directivo & 2 & $1,0 \%$ \\
\hline Procurador & 2 & $1,0 \%$ \\
\hline Propietario & 2 & $1,0 \%$ \\
\hline Adherente & 1 & $0,5 \%$ \\
\hline Candidato a presidente & 1 & $0,5 \%$ \\
\hline Coordinador de Información & 1 & $0,5 \%$ \\
\hline Crítico literario & 1 & $0,5 \%$ \\
\hline Diputado & 1 & $0,5 \%$ \\
\hline Dramaturgo (artista) & 1 & $0,5 \%$ \\
\hline Economista Principal & 1 & $0,5 \%$ \\
\hline Exdiputado & 1 & $0,5 \%$ \\
\hline Filósofo & 1 & $0,5 \%$ \\
\hline Funcionario & 1 & $0,5 \%$ \\
\hline Fundador & 1 & $0,5 \%$ \\
\hline Inversor & 1 & $0,5 \%$ \\
\hline Vice Rector & 1 & $0,5 \%$ \\
\hline Jepartamento de Economía & 1 & $0,5 \%$ \\
\hline Jefe del Deparion & 1 & $0,5 \%$ \\
\hline Miembro del Consejo Asesor & 1 & $0,5 \%$ \\
\hline Miembro del Consejo de Administración & 1 & $0,5 \%$ \\
\hline Presbítero & 1 & $0,5 \%$ \\
\hline Reverendo & 1 & $0,5 \%$ \\
\hline Secretario & 1 & $0,5 \%$ \\
\hline Correspondiente en Madrid & $0,5 \%$ \\
\hline
\end{tabular}

Fuente: Elaboración propia en base a Ideas Sobre la Libertad Nº1 a 54. (1) La cantidad relativa está dada por el número de artículos.

La información disponible en la Tabla 4 nos permite observar:

- Una fuerte preeminencia de cargos de alta jerarquía institucional en los escritores de Ideas Sobre la Libertad en los organismos de los cuales forman parte. Desempeñan, en las instituciones en las que participan, el cargo de presidente en un $15 \%$, vicepresidente en un $2 \%$, directivo en un $9,5 \%$, rector en un $1,5 \%$, vice rector en un $0,5 \%$ y decano en un $2 \%$-;

- Una intensa presencia de miembros del hacer cultural y discursivo en toda la gradualidad del espectro intelectual en el sentido gramsciano -profesores en un $22,9 \%$, investigadores en un $2,5 \%$, periodistas en un $5 \%$, redactores periodísticos en un $2,5 \%$, editores en un $1 \%$, dramaturgos en $0,5 \%$, críticos literarios en un 0,5\%, religiosos -presbíteros en un 0,5\% y reverendos en un $5 \%-$,

- Así como de, en menor número, funcionarios públicos (candidatos a presidente en un 0,5\%, diputados en un 0,5\%; exdiputados en un 0,5\%, funcionarios en ejercicio en un $0,5 \%$ ) y empresarios (empresarios en un $1,5 \%$., propietarios en un $1 \%$ e inversores en un $0,5 \%$ ). 
El análisis hasta aquí efectivizado de los artículos publicados en Ideas Sobre la Libertad, permite replicar la estructura monpelerinesa como una organización que nuclea a distintos sectores sociales al servicio del establecimiento de un orden discursivo que garantice la instauración y mantenimiento del orden neoliberal. Nos permite observar a las mismas como instancias de fuerte articulación política, alejadas de la pretendida objetividad y neutralidad valorativa desde las cuales el saber científico y el movimiento montelerines pretende presentarse.

\section{CONCLUSIONES}

El trabajo que nos disponemos a concluir ha relevado, para disposición del lector y demás investigadores abocados al estudio del neoliberalismo como movimiento político, empresarial e intelectual, los autores cuya obra ha sido difundida en la publicación periódica del Centro de Difusión de la Economía Libre - posteriormente denominado Centro de Estudios Sobre la Libertad-, la revista Ideas Sobre la Libertad, en el periodo en que fue editada, diciembre de 1958 a diciembre de 1989. Así como, la procedencia institucional de los mismos, el carácter de tales instituciones y la posición jerárquica que los mismos ocupaban en las entidades de origen, aquellos que Michel Foucault (2002) denomina instancias de delimitación discursiva.

Ello con objeto de dar cuenta del entramado institucional destinado a brindar - a los distintos centros que diversos integrantes del Mont Pèlerín Society fundaban en distintas partes del globo- un entramado discursivo que les permita - en su espacio local- dar combate en el plano de la significación e interpretación de la realidad social al avance del comunismo, el estado de bienestar, el socialismo y a las diversas formas que se asimilaban a ellos y que, a su entender, ponían en jaque el capitalismo en la modalidad en que deseaban implementar.

Los integrantes de Mont Pèlerin Society crean diversos institutos a lo largo de América Latina y el globo a mediados del siglo XX. El Centro de Difusión de la Economía Libre, dirigido por el monpelerines Alberto Benegas Lynch, es uno de ellos. Esta institución difunde publicaciones periódicas, como la aquí analizada, publicaciones no periódicas, artículos distribuidos en la prensa local y conferencias (de Büren, 2014).

El análisis de los autores cuyos trabajos eran reproducidos en ISL nos ha permitido observar que con cierta preeminencia pertenecían a la Escuela Austriaca de Economía -una de las Escuelas fundadoras de Mont Pèlerin Society juntos a la Escuela de Chicago y la Economía Social de Mercado-, que no se constituían sólo en intelectuales abocados al pensamiento abstracto y la reflexión teórica, sino también en empresarios, dirigentes de asociaciones empresarias y funcionarios públicos.

El abordaje de la procedencia institucional de los autores ha evidenciado que sus trabajos no eran elaborados sólo con el auspicio y sostén material de espacios meramente académicos $\mathrm{y} / \mathrm{o}$ neutrales; sino fundamentalmente desde ámbitos empresariales, periodísticos, políticos y religiosos y desde tanques de pensamientos. Ello no significa que dejen el campo académico y cultural libre de intervención, este 
De Büren, M. P. Disputas discursivas. Ideas sobre la libertad en los desembarcos iniciales del movimiento neoliberal en Argentina

también constituye un espacio de batalla, en tanto lugar de formación y difusión discursiva y construcción de sentido.

La indagación en torno a la posición de los autores en las instituciones desde las que escribían muestra el carácter dirigencial de los mismos, sea en el ámbito empresarial o académico, en tanto, presidentes de empresas y conglomerados empresarios o rectores.

Desde el estudio de un caso, de una publicación local, hemos podido observar el carácter de las prácticas desarrolladas desde Mont Pèlerin Society, del entramado discursivo por ella elaborado y la articulación estratégica que se propone para la defensa de intereses de un sector especifico del capitalismo del siglo XX.

Finalmente, agregamos como invitación a profundizar en torno a la vinculación del trabajo antes desarrollado con la actual circulación de fake news, con reflexiones en torno a procesos de desinformación por saturación de noticias y con lo que - en Argentina- actualmente se denomina pos verdad -nominación últimamente utilizada para caracterizar a las formulaciones enunciativas provenientes de las derechas locales y los medios de comunicación que las acompañan- que un relevo contemporáneo del agrupamiento que analizó este trabajo nos llevaría a abordar por un lado, la Escuela Superior de Economía y Administración de Empresas (ESEADE), institución que fundase Alberto Benegas Lynch (hijo) en 1978 con ayuda financiera de empresarios vinculados a la Bolsa de Comercio de Buenos Aires con objeto de dar continuidad a la labor que antes desarrollase su padre en el Centro de Difusión de la Economía Libre (Benegas Lynch, 2007) y, por otro lado, la Fundación Libertad, institución que se encargase de organizar la reunión de Mont Pèlerin Societyen Argentina en el año 2011 (Fundación Libertad, 2011) en la que estuvieron invitados Mauricio Macri e institución que otorgase su premio Libertad, tras el triunfo electoral del mencionado, a Jorge Lanata en su cena de fin de año de 2015. Homenaje al periodista que contó con las palabras del recién electo presidente y de Mario Vargas Llosa, importante miembro de la Sociedad (Macri, 2015; Fundación Libertad, 2015)

\section{REFERENCIAS}

La Nación. (1999, 20 de febrero). Alberto Benegas Lynch. El sepelio. http://www.lanacion.com.ar/128581-alberto-benegas-lynch

Anderson, P. (2003). Más allá del neoliberalismo: lecciones para la izquierda. En E. Sader y P. Gentili (Comps.). La trama del neoliberalismo. Mercado, crisis y exclusión social. pp. 192-194. Buenos Aires: CLACSO. http://bibliotecavirtual.clacso.org.ar/ar/libros/trama/ander.rtf

Arathoon, H. (1986). Derecha e izquierda: conveniencia de precisar los términos. Ideas Sobre la Libertad, 49, 17-20. 
De Büren, M. P. Disputas discursivas. Ideas sobre la libertad en los desembarcos iniciales del movimiento neoliberal en Argentina

Benegas Lynch, A. (2007). Nuestra historia. ESEADE. http://www.eseade.edu.ar/institucional/institucional/nuestra-historia.html

Benegas Lynch, A. (1979). La causa más noble: la de la libertad. Ideas Sobre la Libertad, 38, 21-24.

Benegas Lynch, A. (1980). Cuatro décadas de estatismo en Latinoamérica. Ideas Sobre la Libertad, 39, 35-50.

Convocatoria Monográfico No 154: Estrategias de desinformación: Fake News y FactChecking. (2021). Revista de Comunicación de la SEECI. http://www.seeci.net/revista/index.php/seeci/issue/view/58

De Büren, M. P. (2013). Mont Pèlerin Society en la articulación del discurso neoliberal. En H. Ramirez (Coord.), O neoliberalismo sul-americano em clave transnacional: enraizamento, apogeu e crise. (pp. 118-143). São Leopoldo: Oikos; Editora EDUNISINOS.

De Büren, M. P. (2014). La Escuela Austríaca de economía, expansión y difusión de sus ideas fuerza. Argentina 1959 - 1989 (Tesis inédita de doctorado), Universidad de Buenos Aires, Facultad de Ciencias Sociales, Buenos Aires]

De Büren, M. P. (2015). Mont Pèlerin Society, un espacio de articulación. En S. Murillo (Coord.), Neoliberalismo y gobiernos de la vida. Diagrama global y despliegues en Argentina y América Latina. (pp. 65-94) Buenos Aires: Editorial Biblos.

De Büren, M. P. (2018). Ludwig von Mises, disputas de significación en la estrategia neoliberal. En Entramados y Perspectivas. Revista de la Carrera de Sociología, 8 (8), 450-494.

https://publicaciones.sociales.uba.ar/index.php/entramadosyperspectivas/issue/vie $w / 330$

De Büren, M. P. (2019). Neoliberalismo, el secreto como estrategia. RevIISE. Revista de Ciencias Sociales y Humanas, 13, 77-90.

De Büren, M. P. (2020). Contra ofensiva neoliberal. La Escuela Austriaca de Economía en el centro estratégico de la disputa. Buenos Aires: CLACSO; IIGG.

De Büren, M. P. (2020). Elementos para una genealogía del movimiento neoliberal en Argentina: intelectuales, políticos y empresarios. Revista Temas Sociológicos, 27, 59-89. http://ediciones.ucsh.cl/ojs/index.php/TSUCSH/issue/view/212

Denord, F. (2002). Le prophète, le pèlerin et le missionnaire. La Circulation internationale du néo-libéralisme et ses acteurs. Actes de la recherche en sciences sociales, 145(5), 9-20. https://doi.org/10.3917/arss.145.0009

Foucault, M. (1979). Microfísica del poder. La Piqueta. 
De Büren, M. P. Disputas discursivas. Ideas sobre la libertad en los desembarcos iniciales del movimiento neoliberal en Argentina

Foucault, M. (2002). La arqueología del saber. Buenos Aires: Siglo XXI.

Foucault, M. (2008). El nacimiento de la biopolítica: curso en el Collège de France: 1978-1979. Buenos Aires. Fondo de Cultura Económica.

Hartwell, R. M. (1995). A History of the Mont Pèlerin Society. Indianapolis: Liberty Fund.

Juárez Paz, R. (1978). Sobre la educación y el analfabetismo. Ideas Sobre la Libertad, 36, 55-59.

Morresi, S. (2008). La nueva derecha argentina: la democracia sin política. Los Polvorines: Universidad Nacional General Sarmiento; Biblioteca Nacional.

Murillo, S. (coord.) (2015). Neoliberalismo y gobiernos de la vida. Diagrama global y despliegues en Argentina y América Latina. Buenos Aires: Biblos.

Murillo, S. (2015a). Biopolítica y procesos de subjetivación en la cultura neoliberal. En S. Murillo (Coord.), Neoliberalismo y gobiernos de la vida. Diagrama global y despliegues en Argentina y América Latina (pp. 17-40). Buenos Aires: Editorial Biblos.

Murillo, S. (2018). Neoliberalismo: Estado y procesos de subjetivación. Entramados y Perspectivas. Revista de la Carrera de Sociología, 8 (8), 392-426. https://publicaciones.sociales.uba.ar/index.php/entramadosyperspectivas/issue/cu $\underline{\text { rrent }}$

Steinberg, J. (1995). The Legacy of Friedrich von Hayek: Fascism Didn't Die with Hitler. The American Almanac. http://american almanac.tripod.com/vonhayek.htm

\section{AUTORA:}

\section{María Paula de Büren:}

Dra. en Ciencias Sociales, Mgter. en Desarrollo Económico para América Latina y Licenciada en Economía. Se desempeñó en el campo de la docencia e investigación en diversas universidades (UBA; UNPAZ; UNVM). Financió sus estudios de posgrados, a través de, becas doctorales y posdoctorales CONICET y Beca de matrícula y manutención de la Universidad Internacional de Andalucía. Publicó numerosos escritos que versan sobre lo que Foucault entiende como arte de gobierno neoliberal. Problemática en la cual focalizó sus estudios doctorales, donde analizó las principales ideas fuerza de una de las corrientes centrales del movimiento neoliberal: la Escuela Austriaca de Economía, así como, las estrategias internacionales desempeñados para su ascenso hegemónico y su arribo al espacio argentino.

ORCID https://orcid.org/0000-0002-4234-0287 